\title{
Aggressive Treatment of Brain Metastasis Increases Survival in Patients with Lung Cancer
}

\author{
Peter Hatlen $^{1 *}$, Tore Amundsen ${ }^{1,2}$, Sveinung Sørhaug ${ }^{1,2}$, Håkon Leira ${ }^{1,2}$, Müller Tomm B ${ }^{3}$, Ruby Mahesparan ${ }^{4}$ and Harald H Hjelde ${ }^{1}$ \\ ${ }^{1}$ Department of Thoracic medicine, St. Olavs Hospital HF, 7006 Trondheim University Hospital, Norway \\ ${ }^{2}$ Department of Circulation and Medical Imaging, Faculty of Medicine, NTNU, 7489 Trondheim, Norway \\ ${ }^{3}$ Department of Neurosurgery, St. Olav's Hospital, 7006 Trondheim University Hospital, Norway \\ ${ }^{4}$ Department of Head and neurosurgery, Haukeland University Hospital, Helse Bergen, 5021 Bergen, Norway
}

\begin{abstract}
Introduction: In selected patients superior survival has been observed when treated aggressively for lung cancer and brain metastasis (BM). The aim of the study was to evaluate treatment-modalities and survival in our region retrospective.

Method: Retrospectively we compared survival for lung cancer patients treated either with microsurgery or Gamma knife surgery (GKS) for BM to a control group $(\mathrm{N}=510)$ patients with lung cancer stage IV and a mean age of 68 years

Results: 42 patients with non-small cell lung cancer were included, $22(52 \%)$ treated with microsurgery and 20 (45\%) with GKS for BM. Patients treated aggressively for lung cancer and BM had a significant survival-benefit, 21 months (Cl 95\%: 9.4-32.6) vs. 4 months in the control group (Cl 95\%: 3.5-4.5) $(p<0.001)$. Treatment with microsurgery showed a survival-benefit compared to GKS, 33 months (Cl 95\%: 15.7-50.2) vs. 15 months (Cl 95\%: 6.0-23.9). A later onset of BM was associated with a survival-benefit 24.6 months (CI 95\%: 18.6-30.6) vs. 10.2 months (Cl 95\%: 4.4-16.1). Prognostic factors were age and the number of BM however patients with 3-4 BM had still a survival benefit (20\% 2 years survival) compared to stage IV.
\end{abstract}

Conclusion: Lung cancer patients with BM, also more than 1, show a significant better overall survival after receiving aggressive BM treatment. The size of the BM seems to be less important.

Keywords: Lung cancer; Brain metastases; Survival; Prognosis; Microsurgery; Gamma knife surgerys

\section{Introduction}

Lung cancer is the leading cause of death of all cancer [1]. Metastatic lung cancer generally has a poor prognosis, with $0-1 \% 5$ years survival [2]. Systemic therapy is the mainstay of treatment. Brain metastases (BM) in patients with lung cancer are common. Approximately $30 \%$ to $55 \%$ of the patients will develop BM [3]. The TNM classification defines patients with BM as stage IV [4]. It has been shown that patients who develop BM later seem to have a better overall survival compared to patients with BM at diagnosis of their lung cancer [5]. In 1996 the first studies showed a survival benefit in selected patients treated aggressively for both lung cancer and BM [6]. Accordingly aggressive treatment of $\mathrm{BM}$ is now a common trend, mainly in patients with oligometastatic disease. However, data about the benefit in patients with more than one $\mathrm{BM}$ treated aggressively are rare and no clear guidelines exist how to treat these patients.

Different treatment options have been evaluated in studies. Radiotherapy alone or in combination with target therapy (EGFR-TKI) seems not to improve the survival, 3-4 month vs. 6 month respectively $[7,8]$. Chemotherapy was believed to have a limited role because of the opinion that chemotherapy does not cross the blood brain barrier. However, studies show an improved survival in patients treated with chemotherapy, 15 month vs. 4 month [9].

The survival rates in patients with $\mathrm{BM}$ treated with ablative therapy, like surgical metastatectomy (resection), Stereotactic Ablative Radiotherapy (SABR), or Gamma knife Surgery (GKS), is highly variable but seems to be better in highly selected patients [10] compared to other treatment options. One study showed a 5 year survival in these patients is about $20 \%$ [11]. In one study the 2 year survival was $54 \%$ [12]. Different prognostic factors are discussed in the literature. It seems that the size of the larges metastasis and the total volume is more important than the total numbers of BM in radiosurgery [13]. Other significant favorable prognostic factors appear to be female gender, adenocarcinoma, a small number of BM (1-3) and absent extra cranial metastases [14]

The aim of our study was to evaluate treatment modalities (microsurgery and GKS), prognostic factors affecting the survival in patients with lung cancer and brain metastasis in our lung cancer population and to describe our experience in this field.

\section{Patients and Methods}

\section{Study population}

In the period January 2006 to December 2014 all patients coded with the International Classification of Diseases (ICD) ICD-10 codes C34.0-C34.9 (lung cancer) and C79.3 (brain metastasis) and the NOMESCO Classification of Surgical Procedures (NCSP) code AAB00 or AAB10 (resection of brain metastasis) were identified with the help of our patient administrative system (PAS) and evaluated for this study. Patients from our region who were referred to the University hospital in Bergen for treatment with GKS in the period 2006 to 2014 were evaluated for this study as well. After the medical journals were reviewed patients were included who had received both curative treatment for their lung cancer (surgery or radio chemotherapy) and either surgical or GKS treatment for their brain metastasis.

*Corresponding author: Peter Hatlen, PhD, MD, Department of Thoracic medicine, St. Olavs Hospital HF, Trondheim University Hospital, Pb 3250 Sluppen, N-7006 Trondheim, Norway, Tel: 0047-90086043; E-mail: Peter. Hatlen@ntnu.no

Received June 22, 2015; Accepted July 02, 2015; Published July 13, 2015

Citation: Hatlen P, Amundsen T, Sørhaug S, Leira H, Tomm MB, et al. (2015) Aggressive Treatment of Brain Metastasis Increases Survival in Patients with Lung Cancer. J Pulm Respir Med 5: 271. doi:10.4172/2161-105X.1000271

Copyright: $\odot 2015$ Hatlen $P$, et al. This is an open-access article distributed under the terms of the Creative Commons Attribution License, which permits unrestricted use, distribution, and reproduction in any medium, provided the original author and source are credited. 
The survival data have been compared with published survival data for lung cancer patients in stage IV from the middle region of Norway $(\mathrm{N}=510)$, further in the article called control population.

\section{Study variables}

The following study variables were registered: Sex, age at the time of lung cancer diagnosis, $\mathrm{T}$ and $\mathrm{N}$ stage, numbers of $\mathrm{BM}$ and the diameter of the largest BM (measured by CT scan or MRI) and the type of treatment modality for BM (microsurgery or GKS). The Charlson index [15] was calculated for each participant and included in the analysis.

Approximately 650,000 people lived in this region in 2010. This population is considered representative of the Norwegian population, but the region lacks larger cities, has a lower educational and income level, and the proportion of smokers is slightly below the mean in Norway.

\section{Statistical analysis}

The Kaplan-Meier method was used to compare the overall survival (OS) rate, from the date of lung cancer diagnoses, in the study population to the control population. Additionally the 1-year, 2-year and 3-year survival rates were calculated. When the Log Rank test showed statistically significant differences for survival we used the adjusted Cox Regression model to adjust for confounders mentioned above. Between groups differences in known prognostic factors were tested with the chi-square test. Hazard ratio (HR) is reported with $95 \%$ confidence interval (CI), and statistical significance was defined as $p$ $\leq 0.05$ (two-sided). Statistical analyses were performed using PASW version 22 (Predictive Analytics Soft Ware IBM Corporation, New York 10589, USA).

\section{Ethical Considerations}

The Regional Committee for Medical and Health Research Ethics have approved the current study (REK\# 2014/1801).

\section{Results}

After reviewing all medical journals and exclusion 42 patients (study population) with non-small-cell lung carcinoma (NSCLC) were included in our study. The demographical characteristics are given in Table 1 . The control population $(\mathrm{N}=510)$ had a mean age 68 years (Table 1).

Patients treated with GKS had a significant higher $\mathrm{N}$ stage compared to the patients treated with microsurgery for $\mathrm{BM}(p=0.003)$.

No significant difference between patients treated with microsurgery and GKS was found in sex $(p=0.802)$, age at lung cancer diagnosis $(p=0.624)$, Charlson index $(p=0.331)$, PS $(p=0.332)$, numbers of BM $(p=0.097)$ and T stage $(p=0.606)$.

The size of the $\mathrm{BM}$ in patients treated with microsurgery was significantly larger $(p<0.001)$ compared to patients treated with GKS.

The numbers of $\mathrm{BM}$ in patients treated with microsurgery varied from one to four, the mean size of the largest lesion was $36 \mathrm{~mm}$ (rang: 5-60 $\mathrm{mm}$ ). In patients treated with GKS the number varied from one to three and the mean size was $16 \mathrm{~mm}$ (rang: $4-29 \mathrm{~mm}$ ). Table 2 shows the characteristics of the BM in all patients in the study population.

The exact cause of death in both the study population and the controls was unknown (Table 2).

\section{Overall survival}

First: The Kaplan-Meier survival analysis showed a significant increased overall survival (OS) in the study population compared to the control population $(p<0.001)$. Median OS was 21 months (CI 95\%: 9.4-32.6) vs. 4.0 months (CI 95\%: 3.5-4.5), respectively.

The 1-year, 2-year and 3-year survival for patients in the study population vs. the control population were $67 \%$ vs. $12 \%, 46 \%$ vs. $3 \%$ and $30 \%$ vs. $0 \%$, respectively. The overall 5 years survival in the study population was $20 \%$.

Second: The Kaplan-Meier survival analysis showed a significant increased OS in patients treated with microsurgery compared to patients treated with GKS. Median OS was 33 months (CI 95\%: 15.750.2 ) vs. 15 months (CI 95\%: 6.0-23.9), respectively ( $p=0.028$ ) (Figure $1)$.

The 1-year, 2-year and 3-year survival for patients treated with microsurgery vs. GKS were $80 \%$ vs. $52 \%, 60 \%$ vs. $29 \%$ and $40 \%$ vs. $14 \%$, respectively. The overall 5 years survival in the microsurgery group was $27 \%$.

In our study population we found a cross over (microsurgery/GKS) in 4 patients. 4 patients treated with microsurgery had been treated additional with GKS in the course of their disease. None of the patients treated with GKS has been treated with microsurgery.

However when excluding these four patients from the analyses microsurgery shows a prolong survival compared to GKS. The median survival for microsurgery 28 months (95\% CI: 13.4-42.5) vs. 15 months (95\% CI: 6.0-23.9).

Patient treated with microsurgery did not receive statistical significant more total brain radiation $(p=0.859)$.

\begin{tabular}{|c|c|c|c|}
\hline & & $\begin{array}{c}\text { Microsurgery } \\
\text { N 23 }\end{array}$ & $\begin{array}{c}\text { Gammaknivsurgery } \\
\text { N 21 }\end{array}$ \\
\hline Sex & Male & $14(60 \%)$ & $12(57 \%)$ \\
\hline Mean age* & Female & $9(40 \%)$ & $9(43 \%)$ \\
\hline Charlson index $^{*}$ & 0 & $61(44-78)$ & $63(48-78)$ \\
\hline & $1-2$ & 15 & 12 \\
\hline & $>2$ & 7 & 5 \\
\hline T-stage & 1 & 1 & 4 \\
\hline & 2 & 5 & 3 \\
\hline & $>2$ & 13 & 11 \\
\hline N-stage & 0 & 3 & 6 \\
\hline & 1 & 12 & 1 \\
\hline & 2 & 6 & 5 \\
\hline & 3 & 3 & 8 \\
\hline
\end{tabular}

$\mathrm{N}$ : Numbers; * in years

Table 1: Characteristics of lung cancer patients with brain metastasis in our study in the two treatment groups (microsurgery and Gamma knife surgery). Patients treated with microsurgery had more often a lower N-stage in our study compared to patients treated with Gamma knife surgery.

\begin{tabular}{|c|c|c|c|c|c|}
\hline N BM & N patients & \% & Size of BM & N patients & $\%$ \\
\hline 1 & 32 & 73 & $15-J a n$ & 11 & 26 \\
\hline 2 & 7 & 16 & $16-30$ & 19 & 44 \\
\hline 3 & 3 & 7 & $31-45$ & 6 & 14 \\
\hline 4 & 2 & 4 & $>45$ & 7 & 16 \\
\hline
\end{tabular}

BM: Brain Metastasis; N: Numbers.

Table 2: Characteristics of the BM: distribution by the number of as well as the size of the BM, in all lung cancer patients (treated with microsurgery and Gamma knife surgery). As shown most common were 2 or less numbers of BM, and a size below $30 \mathrm{~mm}$ in diameter. 
Citation: Hatlen P, Amundsen T, Sørhaug S, Leira H, Tomm MB, et al. (2015) Aggressive Treatment of Brain Metastasis Increases Survival in Patients with Lung Cancer. J Pulm Respir Med 5: 271. doi:10.4172/2161-105X.1000271

Page 3 of 5

Third: Lung cancer patients who had BM at the time of lung cancer diagnosis $(\mathrm{N}=11)$ had a significantly poorer survival compared to patients developing BM later in the course of the disease $(\mathrm{N}=23)$. Mean OS 10.2 months (95\% CI: 4.4-16.1 month) vs. 24.6 months (95\% CI: 18.6-30.6) $(p=0.003)$ (Figure 1).

\section{Survival by confounders}

Patients with one BM $(\mathrm{N}=32)$ had a median survival of 26 months (CI 95\%: 8.5-43.4) compared to patients with two $\mathrm{BM}(\mathrm{N}=7)$ of 12 months (CI 95\%: 0-24.8). Patients with more than two BM $(\mathrm{N}=5)$ had a median OS of 8 months (CI 95\%: 0-22.7). The 1-year, 2-year and 3-year survival for patients with one BM compared to patients with two were $60 \%$ vs. $43 \%, 48 \%$ vs. $14 \%$ and $32 \%$ vs. n-a. $\%$, respectively.

No difference in OS was found in patients with $\mathrm{BM} \leq 40 \mathrm{~mm}$ $(\mathrm{N}=34)$ compared to patients with $\mathrm{BM}>40 \mathrm{~mm}(\mathrm{~N}=9)$. Tab 3 shows the 1,2 and 3 years survival and the median survival.

Patients with T 1-2-stage $(\mathrm{N}=32)$ had a significantly increased OS compared to patients with T3-4-stage ( $\mathrm{N}=9)$. Median OS 28 months (CI 95\%: 17.2-38.8) vs. 14 months (CI 95\%: 0-37.6) $(p=0.012)$. No survival benefit between T1-stage $(\mathrm{N}=8)$ and $\mathrm{T} 2$-stage $(\mathrm{N}=24)$ was found ( $p=0.995$ ) (Table 3).

No significant difference in survival was found between patients with $\mathrm{N}-1$ and $\mathrm{N} 2$ disease $(\mathrm{N}=15)$, however the OS was significantly

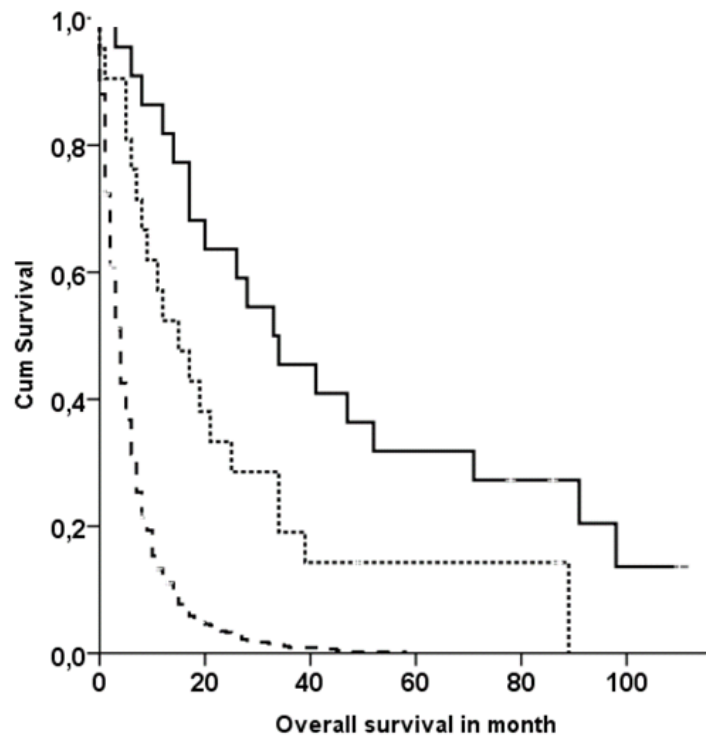

Figure 1: Kaplan-Meier survival curves for the study population divided into the two treatment modalities (microsurgery and Gamma knife surgery) and patients with lung cancer at stage IV. Patients treated with microsurgery seem to have superior survival compared to patients treated with Gamma knife surgery. However both treatment modalities have a superior survival compared to patients with lung cancer stage IV.

\begin{tabular}{|c|c|c|c|c|c|}
\hline Size brain metastasis & $\mathbf{N}$ & 1 year & 2 year & 3 year & Median survival $^{\text {a }}$ \\
\hline $0-40 \mathrm{~mm}$ & 34 & $67 \%$ & $45 \%$ & $30 \%$ & 26 \\
\hline$>40 \mathrm{~mm}$ & 9 & $67 \%$ & $44 \%$ & $22 \%$ & 23 \\
\hline
\end{tabular}

Table 3: The 1, 2 and 3 year survival by diameter $(0-40 \mathrm{~mm}$ and $>40 \mathrm{~mm})$ of the largest metastasis in patients with lung cancer. As shown also patients with BM $>40 \mathrm{~mm}$ have a superior survival compared to patients with lung cancer stage IV. (Including all lung cancer patients, treated with microsurgery or Gamma knife surgery). reduced in patient with $\mathrm{N} 3$ disease $(\mathrm{N}=8)$ compared to $\mathrm{N} 1-2$ disease $(p=0.008)$.

The median OS in N0 disease $(\mathrm{N}=18)$ stage was 34 months (CI 95\%: 12.4-55.5), N1 disease (N=7) 26 months (CI 95\%: 10.6-41.4), N2 disease $(\mathrm{N}=8) 17$ months (CI 95\%: 0-47.5) and N3 disease 8 months (CI 95\%: 2.4-13.5).

In the study population there was no significant difference in the OS rate between male and female. The median OS in males $(\mathrm{N}=26)$ was 26 months (95\% CI: 13.0-38.9) vs. in females $(\mathrm{N}=18) 17$ months $(95 \%$ CI: $10.0-23.7),(p=0.226)$.

\section{The regression model}

In the univariable regression model male sex, younger age, microsurgery for $\mathrm{BM}$, low $\mathrm{N}$-disease and T-stage were significant positive prognostic factors for OS, Table 4.

Including confounders in the multi regression model only age at diagnosis and the numbers of BM were significant prognostics factors. T-stage and the time between diagnosis of lung cancer and the occurrence of BM were borderline significant prognostics factors, Table 4.

\section{Discussion}

Our study shows that patients treated for BM and curative treatment for lung cancer have a superior survival benefit compared to the control population (lung cancer patients in stage IV) receiving standard treatment. Several retrospective studies have reported a prolonged survival in patients with lung cancer and single BM who have been treated with microsurgery for $\mathrm{BM}$ and lung cancer. The reported 5 year survival in the literature varies from 7-27\% [16-18] and is in line with our results, that was $20 \% 5$ years survival.

Also patients with more than one BM have an improved OS rate in our population compared to the control population. Only a few studies have included patients with more than one BM. One study has been published showing that also patients with more than one BM benefit from an aggressive treatment [12]. However no European guidelines, including the Norwegian guidelines, currently exist which recommend aggressive treatment in patients with more than one BM $[19,20]$. In our study population patients with $2 \mathrm{BM}$ had a median OS with 12 months and a $14 \% 2$ years survival. This result may indicate that patients with more than one BM may also benefit from a more aggressive treatment and should be considered as well.

\begin{tabular}{|c|c|c|c|c|c|c|}
\hline & \multicolumn{3}{|c|}{ univariable } & \multicolumn{3}{c|}{ multivariable } \\
\hline & $\boldsymbol{p}$-value & HR & Cl 95\% & $\boldsymbol{p}$-value & HR & CI 95\% \\
\hline Sex (male vs. female) & 0.015 & 1.24 & $1.04-1.48$ & 0.133 & 1.94 & $0.82-4.58$ \\
\hline Charlson index & 0.172 & 1.18 & $0.93-1.51$ & 0.850 & 1.03 & $0.76-1.41$ \\
\hline Age at diagnosis & 0.026 & 1.01 & $1.00-1.02$ & 0.046 & 1.05 & $1.00-1.09$ \\
\hline Treatment BM & $<0.001$ & 1.83 & $1.57-2.12$ & 0.122 & 2.35 & $0.79-6.94$ \\
\hline N-stage & 0.008 & 1.55 & $1.23-2.13$ & 0.284 & 1.24 & $0.84-1.82$ \\
\hline T-stage & 0.010 & 1.83 & $1.54-2.91$ & 0.058 & 1.69 & $0.98-2.93$ \\
\hline Diameter BM & 0.778 & 0.99 & $0.98-1.02$ & 0.083 & 1.04 & $0.99-1.08$ \\
\hline Number BM & 0.101 & 1.34 & $0.95-1.89$ & 0.025 & 1.76 & $1.07-2.89$ \\
\hline $\begin{array}{c}\text { Time between BM and } \\
\text { lung cancer diagnosis }\end{array}$ & 0.071 & 0.98 & $0.96-1.01$ & 0.052 & 0.97 & $0.94-1.00$ \\
\hline
\end{tabular}

HR: Hazards Ratio; Cl: Confidence Interval; BM: Brain Metastasis.

Table 4: Regression analysis for overall survival in patients treated curatively for lung cancer and brain metastasis including all confounders; on the left the univariable model, on the right the multivariable model. As shown in the multivariable analyses only the age at diagnosis of lung cancer and the numbers of BM were significant factors. 
Results in literature are conflicting whether microsurgery of BM gives a better local control compared to radiation or not $[21,22]$. In our study the longest OS was found in patients treated with microsurgery for their BM compared to patients treated with GKS. These results may be partly explained with a higher $\mathrm{N}$-stage in our patients receiving GKS. A possible cross over between microsurgery and GKS was excluded as an error. However our study population was small and the results must be interpreted with caution.

Many studies have shown that females with lung cancer have a longer OS [23-25]. However we did not find a sex specific difference in OS in our population. This may be explained by our selective study population, selection bias. A possible explanation may also be that our study group was too small to show such difference.

In our study population there was a predominance of males (60\%). We cannot explain this finding since there was no statistical difference between males and females in Charlson index, age, T-stage, $\mathrm{N}$-stadium, numbers of $\mathrm{BM}$ or the maximum size of the $\mathrm{BM}$.

Prognostics factors in our study population were age at diagnosis and the numbers of BM. Patients with a long disease-free interval before the occurrence of BM had a better survival compared to early or simultaneous diagnosis of $\mathrm{BM}$, however aggressive treatment of BM in these patients still yielded a superior OS compared to stage IV disease.

The mean age of our study population was 62 years vs. 71 years in general metastatic lung cancer population. Also the general health in our study populations is probably better compared to the general lung cancer population. However we do not believe that these factors are mainly responsible for the survival benefit.

In our study the OS in lung cancer patients with BM is affected by the stage of lung cancer ( $\mathrm{N}$ stage and $\mathrm{T}$ stage), by the age of the patient and the numbers of BM. In the literature there is still a discussion of what factors are important for the prognosis [16,26,27]. Nearly all studies were retrospective and only with a small number of patients, generating a problem of validity and correct definition of prognostic factors.

Many factors affect survival. Epidermal growth factor (EGFR) and v-Ki-ras 2 Kirsten ras sarcom (KRAS) mutation status has impact on survival [28]. In our population the EGFR status was unknown. On the one hand this can influence the results, one the other none of the patients had received EGFR tyrosin kinase inhibitor (TKI). Furthermore we assume that the distribution of EGFR mutation should be similar in both the study population and control population. The survival benefit seems to be too pronounced for the EGFR status to be the only explanation.

Performance status (PS) may also be prognostic factors but in many of our patients the PS at the time of diagnosis was not registered and therefore a retrospective evaluation of the PS would not be adequate. Since all patients in the study population have been treated with curative intention, we assume that the PS must have been between 0-1 in our study population.

Comorbidity was included in our analysis and seems not to be a prognostic factor when the patients were operable and healthy enough to receive curative treatment.

Aggressive treatment for brain lesions, by microsurgery and/or GKS, showed significantly better outcome in our study as shown in other studies. However, these results do not prove that microsurgery and/or GKS is superior to other treatments. There are many different biases that may have impact on decision making and finding the optimal treatment. The choice of the treatment modality depends on many factors such as PS, number of BM, location and size of the BM and the accessibility. Prospective, randomized studies with well defined criteria at each level are needed to decrease these potential biases, both in selection cases and therapies.

In the treatment of patients with lung cancer, not only survival but also quality of life (QoL) is an important issue and should be remembered when choosing the treatment modality and especially when conducting a future prospective study. We have no information about QoL in our study group neither in our control group. So we do not know how the two treatment modalities (microsurgery and GKS) affect the QoL in our patients.

Further we do not know the cost-benefit of aggressive treatment in these patients.

Both QoL and the cost-benefit aspect are important questionaries. Being a retrospective study, we can not provide an answer to these questions but further studies should include these topics.

There are several limitations of the study. The study population was small, only from one center and the design was retrospective and giving the potential for selection and recall bias. Several studies have shown an association between the EGFR status and survival. Given the time period for our study we have only information in a few patients about the EGFR status. However the main results are consistent with other studies. Further we have no information whether the patients in the study population have received addition treatment (chemotherapy/ thoracic ration). There is an urgent need for prospective studies to confirm the important survival results from several retrospective studies.

\section{Conclusion}

Selected patients with lung cancer and brain metastasis seem to have a prolonged survival when treated aggressively for both the thoracic and cerebral malignity compared to lung cancer patients with stage IV disease. Age and the number of BM were significant prognostic factors. Microsurgery of BM seems to have a survival advantage; however patients treated with GKS have a prolong survival compared to stage IV as well. The size of the BM was less important for survival. Further prospective studies in this field of research are strongly needed. The authors opinion is that all patients with curative treatment for lung cancer and $\mathrm{BM}$, also with more than one $\mathrm{BM}$, should be considered for aggressive treatment for BM.

\section{References}

1. Siegel R, Naishadham D, Jemal A (2012) Cancer statistics, 2012. CA Cancer J Clin 62: 10-29.

2. National Cancer Institute (2000) SEER, Surveillance Epidemiology and End Results.

3. Rodrigus P, de Brouwer P, Raaymakers E (2001) Brain metastases and nonsmall cell lung cancer. Prognostic factors and correlation with survival after irradiation. Lung Cancer 32: 129-136.

4. Rami-Porta R, Bolejack V, Giroux DJ, Chansky K, Crowley J, et al. (2014) The IASLC lung cancer staging project: the new database to inform the eighth edition of the TNM classification of lung cancer. J Thorac Oncol 9: 1618-1624.

5. Ali A, Goffin JR, Arnold A, Ellis PM (2013) Survival of patients with non-smallcell lung cancer after a diagnosis of brain metastases. Curr Oncol 20: e300306

6. Mussi A, Pistolesi M, Lucchi M, Janni A, Chella A, et al. (1996) Resection of single brain metastasis in non-small-cell lung cancer: prognostic factors. $J$ Thorac Cardiovasc Surg 112: 146-153.

7. Cai Y, Wang JY, Liu H (2013) Clinical observation of whole brain radiotherapy 
Citation: Hatlen P, Amundsen T, Sørhaug S, Leira H, Tomm MB, et al. (2015) Aggressive Treatment of Brain Metastasis Increases Survival in Patients with Lung Cancer. J Pulm Respir Med 5: 271. doi:10.4172/2161-105X.1000271

concomitant with targeted therapy for brain metastasis in non-small cell lung cancer patients with chemotherapy failure. Asian Pac J Cancer Prev 14: 56995703.

8. Kaal EC, Niël CG, Vecht CJ (2005) Therapeutic management of brain metastasis. Lancet Neurol 4: 289-298.

9. Kim DY, Lee KW, Yun T, Kim DW, Kim TY, et al. (2005) Efficacy of platinumbased chemotherapy after cranial radiation in patients with brain metastasis from non-small cell lung cancer. Oncol Rep 14: 207-211.

10. Ashworth A, Rodrigues G, Boldt G, Palma D (2013) Is there an oligometastatic state in non-small cell lung cancer? A systematic review of the literature. Lung Cancer 82: 197-203.

11. Qin H, Wang C, Jiang $Y$, Zhang X, Zhang $Y$, et al. (2015) Patients with single brain metastasis from non-small cell lung cancer equally benefit from stereotactic radiosurgery and surgery: a systematic review. Med Sci Monit 21 : 144-152.

12. Gray PJ, Mak RH, Yeap BY, Cryer SK, Pinnell NE, et al. (2014) Aggressive therapy for patients with non-small cell lung carcinoma and synchronous brainonly oligometastatic disease is associated with long-term survival. Lung Cancer 85: $239-244$.

13. Banfill KE, Bownes PJ, St Clair SE, Loughrey C, Hatfield P (2012) Stereotactic radiosurgery for the treatment of brain metastases: impact of cerebral disease burden on survival. Br J Neurosurg 26: 674-678.

14. Sakamoto J, Sonobe M, Kobayashi M, Ishikawa M, Kikuchi R, et al. (2014) Prognostic factors for patients in postoperative brain metastases from surgically resected non-small cell lung cancer. Int J Clin Oncol 19: 50-56.

15. Charlson ME, Pompei P, Ales KL, MacKenzie CR (1987) A new method of classifying prognostic comorbidity in longitudinal studies: development and validation. J Chronic Dis 40: 373-383.

16. Billing PS, Miller DL, Allen MS, Deschamps C, Trastek VF, et al. (2001) Surgical treatment of primary lung cancer with synchronous brain metastases. $\mathrm{J}$ Thorac Cardiovasc Surg 122: 548-553.

17. Bonnette P, Puyo P, Gabriel C, Giudicelli R, Regnard JF, et al. (2001) Surgical management of non-small cell lung cancer with synchronous brain metastases. Chest 119: 1469-1475.
8. Lo CK, Yu CH, Ma CC, Ko KM, Leung SC (2010) Surgical management of primary non-small-cell carcinoma of lung with synchronous solitary brain metastasis: local experience. Hong Kong Med J 16: 186-191.

19. Helsedirektoratet, Nasjonalt handlingsprogram med retningslinjer for diagnostikk, behandling og oppfølging av lungekreft. 2015.

20. Peters S, Adjei AA, Gridelli C, Reck M, Kerr K, et al. (2012) Metastatic nonsmall-cell lung cancer (NSCLC): ESMO Clinical Practice Guidelines for diagnosis, treatment and follow-up. Ann Oncol 23 Suppl 7: vii56-64.

21. Bougie E, Masson-Côté L, Mathieu D (2015) Comparison Between Surgica Resection and Stereotactic Radiosurgery in Patients with a Single Brain Metastasis from Non-Small Cell Lung Cancer. World Neurosurg 83: 900-906.

22. Tian LJ, Zhuang HQ, Yuan ZY (2013) A comparison between cyberknife and neurosurgery in solitary brain metastases from non-small cell lung cancer. Clin Neurol Neurosurg 115: 2009-2014.

23. Innos K, Padrik P, Valvere V (2015) Sex differences in cancer survival in Estonia: a population-based study. BMC Cancer 15: 72.

24. Sagerup CM, Småstuen M, Johannesen TB, Helland Å, Brustugun OT (2011) Sex-specific trends in lung cancer incidence and survival: a population study of 40,118 cases. Thorax 66: 301-307.

25. Ulas A, Tokluoglu S, Kos M, Silay K, Akinci S, et al. (2015) Lung cancer in women, a different disease: survival differences by sex in Turkey. Asian Pac $J$ Cancer Prev 16: 815-822.

26. Collaud S, Stahel R, Inci I, Hillinger S, Schneiter D, et al. (2012) Survival of patients treated surgically for synchronous single-organ metastatic NSCLC and advanced pathologic TN stage. Lung Cancer 78: 234-238.

27. Yuksel C, Bozkurt M, Yenigun BM, Enon S, Ozkan M, et al. (2014) The outcome of bifocal surgical resection in non-small cell lung cancer with synchronous brain metastases: results of a single center retrospective study. Thorac Cardiovasc Surg 62: 605-611.

28. Cadranel J, Mauguen A, Faller M, Zalcman G, Buisine MP, et al. (2012) Impact of systematic EGFR and KRAS mutation evaluation on progressionfree survival and overall survival in patients with advanced non-small-cell lung cancer treated by erlotinib in a French prospective cohort (ERMETIC project-part 2). J Thorac Oncol 7: 1490-1502. 